\title{
A perspectiva freireana \\ na formação permanente de educadores/as
}

\author{
The freirean perspective \\ on permanent teacher training
}

La perspectiva freireana

en la formación permanente de educadores/as

VALTER MARTINS GIOVEDI

Universidade Federal do Espírito Santo, Vitória- ES, Brasil.

ELSON AUGUSTO DO NASCIMENTO**

Sec. Municipal de Educação de Pancas, Pancas- ES, Brasil.

\begin{abstract}
RESUMO: Este artigo busca descrever e analisar princípios e momentos de um processo de formação permanente de educadoras/es do campo fundamentado na perspectiva freireana. A metodologia utilizada foi qualitativa por meio de observação participante de um projeto de formação de professoras/es do campo em um município do Noroeste do Espírito Santo. Apresentamos uma síntese do processo e analisamos os momentos do trabalho de formação a partir dos conceitos freireanos de reflexão crítica sobre a prática, dialogicidade, politicidade, conscientização, participação, currículo e práxis transformadora.

Palauras-chave: Formação de educadores. Formação permanente. Paulo Freire.
\end{abstract}

ABSTRACT: This article seeks to outline and analyze moments and principles of a permanent, rural education, teachers training process

* É professor do Centro de Educação da Universidade Federal do Espírito Santo, atuando como professor do curso de Licenciatura em Educação do Campo e do Mestrado Profissional em Educação. Coordenador do Grupo de Estudos e Pesquisas Paulo Freire (GEPPF). E-mail: <giovedival@gmail.com>.

* É graduado em Letras Português e Pedagogia. Possui mestrado em Educação pela Universidade Federal do Espírito Santo. É professor de ensino fundamental na Secretaria Municipal de Educação de Pancas- ES, onde, atualmente, exerce a função de coordenação/orientador pedagógico social. E-mail:<elsonaugusto2017@gmail.com>. 
based in a Freirean perspective. The methodology which was used was qualitative through participant observation in a project meant to train rural education teachers in the Northwestern part of Espírito Santo. We have introduced a synthesis of the process and have analyzed the moments in the training process based in the Freirean critical reflection concepts about the practice, dialogicity, politicity, awareness, participation, curriculum, and transformative praxis.

Keywords: Teacher training. Permanent training. Paulo Freire.

RESUMEN: Este artículo busca describir y analizar principios y momentos de un proceso de formación permanente de educadoras/ es en el campo desde la perspectiva freireana. La metodología utilizada fue cualitativa a través de la observación participante de un proyecto de capacitación de maestras/os rurales en un municipio del noroeste de Espírito Santo. Presentamos una síntesis del proceso y analizamos los momentos del trabajo formativo a partir de conceptos freireanos de reflexión crítica sobre la práctica, dialogicidad, politicidad, concientización, participación, currículum y praxis transformadora.

Palabras clave: Formación de educadores. Formación permanente. Paulo Freire.

\section{Considerações iniciais}

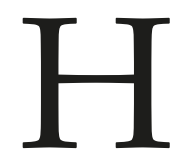
istoricamente, é possível notar que educadoras/es foram submetidas/os a uma cultura de formação, quer seja inicial ou continuada, meramente de lugar de transmissão de uma determinada orientação teórica e especificidades; ou tida como lugar para busca de receitas prontas ou formas de como fazer, ditas por alguém de fora da realidade, que surge como um "vidente", a fim de dar respostas e mostrar caminhos para o fazer daquele grupo em específico, em uma sala de aula abstrata.

Há, ainda, uma cultura de conceber e reduzir a formação à chamada "formação em serviço", entendida como aquele momento que se dá por meio de palestras, aperfeiçoamento, reciclagem, seminários, oficinas e inúmeras outras propostas, em sua maioria organizadas por empresas especializadas em oferta de pacotes privados, prontos para comercialização, com propostas desconectadas do fortalecimento das experiências e processos educativos que colaboram para as mudanças sociais, resolução de problemas, criatividade e criticidade. 
Consequentemente, o que se faz nesses casos são programas de formação em serviço superficiais, marcados por teorizações, que desvinculam o contexto escolar da realidade concreta das/os estudantes e negam ao docente a condição de sujeito ativo do processo de formação, impossibilitando-o de repensar a própria prática e transformá-la a partir de ações concretas.

Essa cultura de formação tem se constituído como uma barreira para as mudanças de caráter pedagógico e das políticas públicas de formação de educadoras/es, cerceando perspectivas reais de qualidade social, de aprendizagem e de transformação da práxis docente. Como afirma Freire (1991), "isso impede de pôr em prática uma educação em favor da emancipação das gentes".

Contra essas perspectivas, Freire ousa afirmar que o processo de formação em serviço precisa dialogar com a experiência de problematização da prática realizada pelas/ os docentes em sala de aula no cotidiano de ensino-aprendizagem.

Fruto de uma pesquisa realizada no nível de mestrado profissional em educação (NASCIMENTO, 2019), este texto tem por objetivo apresentar a síntese dos princípios e momentos que fundamentaram nossa experiência de formação permanente freireana de educadoras/es em um município do Noroeste do Espírito Santo. Com isso, temos a expectativa de contribuir com sugestões e possibilidades para reinventar a formação contínua de educadoras/es, tendo por referencial o paradigma da formação permanente defendido por Paulo Freire.

Além dessas considerações iniciais, dividimos o texto em mais três momentos: no primeiro apresentamos breve reflexão sobre o conceito de formação permanente de Paulo Freire, algumas de suas implicações e um quadro-síntese que construímos como produto do trabalho dissertativo e que representa uma visão global de como reinventamos a perspectiva de Freire para a nossa situação concreta; no segundo, explicamos mais detalhadamente o quadro da seção anterior, a partir dos conceitos que elegemos para sustentar as reflexões e análises: reflexão crítica sobre a prática, dialogicidade, politicidade, conscientização, participação, currículo e práxis transformadora.

\section{O paradigma da formação permanente freireana}

Apresentamos a seguir um trecho de Freire sobre os princípios do paradigma de formação permanente para, em seguida, tecer alguns comentários:

1. O educador é o sujeito de sua prática, cumprindo a ele criá-la e recriá-la.

2. A formação do educador deve instrumentalizá-lo para que ele crie e recrie a sua prática através da reflexão sobre o seu cotidiano. 
3. A formação do educador deve ser constante, sistematizada, porque a prática se faz e se refaz.

4. A prática pedagógica requer a compreensão da própria gênese do conhecimento, ou seja, de como se dá o processo de conhecer.

5. O programa de formação de educadores é condição para o processo de reorientação curricular da escola.

6. O programa de formação de educadores terá como eixos básicos:

- a fisionomia da escola que se quer, enquanto horizonte da nova proposta pedagógica;

- a necessidade de suprir elementos de formação básica aos educadores nas diferentes áreas do conhecimento humano;

- a apropriação, pelos educadores, dos avanços científicos do conhecimento humano que possam contribuir para a qualidade da escola que se quer (FREIRE, 1991: 80).

O paradigma da formação permanente é, na concepção de Freire (1991), uma ação que se dá junto com o exercício da profissão. Por isso, o princípio fundamental é o da práxis, ou seja, a reflexão crítica sobre a prática. A concretização da práxis só é possível quando se garante que os sujeitos da ação sejam também os sujeitos da reflexão sobre a ação. A nova prática que se deseja instituir não poderá ser forjada, senão a partir das reflexões e construções promovidas pelos próprios/as educadoras/es.

O cotidiano do trabalho docente é o objeto que deve mediatizar o trabalho de formação no paradigma da formação permanente. O ponto de partida da formação são sempre as situações-limites do grupo de educadoras/es que emergem de ações dialógicas em momentos de trabalho coletivo, em grupos de formação.

Esse momento coletivo de reflexão crítica sobre a prática, a partir das situações-limites vivenciadas, não ocorre de modo esporádico, em um momento pontual do ano letivo. Para Freire, ele deve ser permanente, de modo simultâneo ao trabalho pedagógico que se dá na sala de aula. Ações de formação pontuais são válidas, porém, têm um poder muito limitado de produzir novas concepções e novas ações.

Freire esforçou-se durante toda a sua obra em sistematizar uma teoria do conhecimento que desse conta de explicar as condições de possibilidade da aprendizagem crítica. Suas reflexões e, sobretudo, suas experiências conduziram-no à convicção de que o diálogo é princípio necessário da aprendizagem. O diálogo é ação de transformação das relações. No contexto da formação de educadores/as, ele possibilita o envolvimento entre atores 
do processo educativo numa constituição formativa permanentemente coesa direcionada ao exercício da interação, da troca do conhecimento e construção de novos saberes.

Nessa perspectiva não é possível dicotomizar a reorientação curricular do processo de formação permanente. Dessa forma, Freire descarta a hipótese de elaborar um currículo para depois ofertar um processo de formação para os professores/as o aplicarem. Muito diferente disso, os educadores/as tornam-se sujeitos criadores do currículo na medida em que o processo de formação vai se realizando.

Na experiência como secretário de educação da cidade de São Paulo, entre 1989 e 1992, Freire percebeu a necessidade de os/as educadores/as terem a oportunidade de compreender que as novas práticas não poderiam estar descoladas da nova concepção de escola que se queria construir; retomar conhecimentos que constituem o seu campo de formação como forma de preencher lacunas de formação e reaprender conhecimentos específicos desenvolvidos no período de formação inicial; acessar os novos conhecimentos que contribuem com a escola que se pretende construir.

A formação permanente é necessariamente coletiva e ocorre por meio de grupos de formação que garantam tanto o trabalho de desconstrução das práticas instituídas, quanto o de construção de alternativas, em especial, de reconstrução coletiva do currículo da escola. Termos clareza desses dois momentos é fundamental para orientar o caminho do planejamento e do desenvolvimento dos encontros formativos.

A partir da experiência na nossa pesquisa foi possível chegar a uma sistematização que entendemos ser uma representação da reinvenção dessa perspectiva formativa.

O quadro a seguir foi o resultado da observação participante (CHIZZOTTI, 2006; BRANDÃO, 1985; MINAYO, 2010) que realizamos do processo de formação permanente freireano junto a educadoras/es do campo. Na próxima seção, pretendemos explicá-lo, já que ele sintetiza o nosso esforço de reinvenção do paradigma freireano da formação permanente.

\section{Tabela 1-Princípios, momentos e submomentos estruturantes de um processo de formação permanente de educadoras/es do campo na perspectiva freireana}




\begin{tabular}{|c|c|c|}
\hline \multirow{3}{*}{$\begin{array}{l}\text { Princípios/ } \\
\text { Conceitos } \\
\text { fundamentais }\end{array}$} & \multicolumn{2}{|c|}{ Momentos da Formação } \\
\hline & Momento de Desconstrução & Momento de Construção \\
\hline & Submomentos: & Submomentos: \\
\hline $\begin{array}{l}\text { 1. Dialogicidade; } \\
\text { 2. Reflexão crítica } \\
\text { da prática; } \\
\text { 3. Participação; } \\
\text { 4. Conscientização; } \\
\text { 5. Politicidade; } \\
\text { 6. Práxis } \\
\text { transformadora; } \\
\text { 7. Currículo. }\end{array}$ & $\begin{array}{l}\text { 1. Comparação de práticas } \\
\text { pedagógicas e levantamento } \\
\text { das situações-limites mais } \\
\text { significativas das educadoras; } \\
\text { 2. Análise crítica das práticas } \\
\text { instituídas; } \\
\text { 3. Educação Libertadora no contexto } \\
\text { escolar; } \\
\text { 4. Análise das práticas e concepções } \\
\text { vigentes na Educação do Campo: } \\
\text { Educação Rural, Educação do } \\
\text { Campo e Educação do Campo na } \\
\text { perspectiva freireana. }\end{array}$ & $\begin{array}{l}\text { 5. Planejamento, organização e } \\
\text { elaboração da estratégia da } \\
\text { investigação das situações- } \\
\text { problemas, falas significativas e } \\
\text { limites explicativos; } \\
\text { 6. Execução da investigação temática } \\
\text { e organização e sistematização } \\
\text { de informações coletadas } \\
\text { na construção de momentos } \\
\text { organizacionais da construção do } \\
\text { currículo e práticas pedagógicas; } \\
\text { 7. Construção da base da rede } \\
\text { temática: tema gerador, falas } \\
\text { significativas e contratema; } \\
\text { 8. Construção das dimensões local, } \\
\text { microssocial e macrossocial da } \\
\text { rede temática; } \\
\text { 9. Construção de programações } \\
\text { e de atividades pedagógicas } \\
\text { contextualizadas. }\end{array}$ \\
\hline
\end{tabular}

Fonte: Elaborado pelos autores.

\section{Uma práxis de reinvenção da formação permanente freireana}

\section{Circunstâncias do trabalho de formação desenvolvido}

A experiência de reinvenção foi realizada com as/os professoras/es e pedagogas/os de salas de aulas de escolas do campo, de um município da região Noroeste do estado Espírito Santo, a partir de um projeto de extensão que estabeleceu parceria entre professoras/es do Centro de Educação da Universidade Federal do Espírito Santo e órgão municipal de educação. $\mathrm{O}$ trabalho de formação se deu entre os meses de maio e novembro de 2018, no decorrer de um ano letivo, no tempo do planejamento das/os educadoras/ es, organizado em encontros quinzenais, com duração média de três horas cada e com a participação de 38 educadoras/es. De acordo com as informações obtidas durante a pesquisa, as/os educadores/as nunca tinham vivenciado uma experiência de formação na perspectiva proposta: concepção freireana articulada à educação do campo. 
Considerando que a pesquisa se deu no contexto de um programa de pós-graduação de mestrado profissional em educação, o compromisso de chegar a um produto educacional estava colocado desde o início do trabalho. A certa altura do desenvolvimento da pesquisa e das reflexões, ficou claro que o nosso produto poderia ser um quadro-síntese de todo o processo realizado durante o trabalho de formação.

Sistematizamos o quadro em duas grandes partes: 1ª Princípios da Formação Permanente Freireana; $2^{-}$Momentos da Formação Permanente Freireana.

Quanto aos Princípios, entendemos como fundantes para direcionar o trabalho formativo: dialogicidade, reflexão crítica da prática, participação, conscientização, politicidade, currículo e práxis-transformadora, organizado através da trama conceitual, inspirado nos pressupostos de Saul (2015). Tais princípios sustentam a interpretação, os valores formativos, a postura da/o formadora/or e dão direção para o olhar e agir críticos e avaliativos. Esses princípios constituíram-se como categorias que fundamentaram o percurso de pesquisa, observação, análise e sustentaram as bases da nossa construção teórica e científica, tendo em vista o que defendemos para repensar e reinventar o desenvolvimento de um programa permanente de formação de educadoras/es.

Quanto aos momentos, inspiramo-nos em Silva (2004; 2007), que propõe que todo trabalho de formação permanente compromissado com a construção coletiva do currículo popular crítico e contextualizado deve garantir dois movimentos reflexivo-criativos: um de desconstrução e outro de construção.

O primeiro busca favorecer que as/os participantes exponham suas situações problemas mais recorrentes em sala de aula, as teorias embutidas a respeito de suas práticas e possibilidades de superação e transformação da realidade. Em suma, é momento de convite a todas/os para o tratamento e busca de compreensão crítica de modelos de práticas pedagógicas dominantes e que tolhem o exercício de uma pedagogia como caminho da liberdade. O segundo momento desenvolve-se como espaço propositivo e de reorientação curricular à luz dos pressupostos freireanos.

Tanto o primeiro quanto o segundo momentos foram organizados por etapas, que definimos como submomentos ou desdobramentos, efetivados nos encontros de formação.

\section{O momento de desconstrução e os seus submomentos}

O momento de desconstrução consiste fundamentalmente no olhar reflexivo das/os educadoras/es sobre as práticas hegemônicas instituídas. Trata-se de uma fase analítica de compreensão científica das questões que envolvem a formação, as situações-problemas expostas pelos participantes, as teorias embutidas nas práticas e as possibilidades de superação. Ainda que todos os princípios estejam presentes em todos os submomentos 
da formação, na nossa análise ganharam maior destaque os princípios da reflexão crítica sobre a prática, da dialogicidade, da politicidade e da conscientização.

A reflexão crítica sobre a prática é um conceito que se evidenciou muito fortemente no primeiro submomento da desconstrução (1. Comparação de práticas pedagógicas e levantamento das situações-limites mais significativas das/os educadoras/es). Ao se depararem com uma atividade em que eram convidadas/os a fazer um trabalho comparativo entre duas práticas pedagógicas, uma de um professor baseado no currículo hegemônico e outro que se pauta por um currículo freireano, as/os educadoras/es realizaram a desnaturalização dos pressupostos e iniciativas do primeiro professor, além de perceberem as diferenças substanciais com o segundo professor, evidenciando que partia de pressupostos teóricos bem diferentes.

A dialogicidade ganhou especial significado no segundo submomento da desconstrução (2. Análise crítica das práticas instituídas). Isso decorreu do fato de que, ao levantarmos as maiores dificuldades nas experiências das/os educadoras/es em sala de aula, tivemos um resultado que nos levou a tocar em questões muito sensíveis do cotidiano do trabalho pedagógico. O quadro abaixo sintetiza as problemáticas.

\section{Tabela 2 - Problemas mais significativos vivenciados pelas/os educadoras/es em sala de aula}

\begin{tabular}{l|c}
\hline Como professor(a), qual a maior problema que você sente no contexto de sala de aula? \\
\hline Problema & $\begin{array}{c}\text { Quantidade de } \\
\text { questionários } \\
\text { que o citaram }\end{array}$ \\
\hline $\begin{array}{l}\text { Diferentes níveis em sala de aula; níveis muito desiguais dos estudantes } \\
\text { (turmas multisseriadas). }\end{array}$ & 7 \\
\hline $\begin{array}{l}\text { Indisciplina; Falta de limites dos educandos. } \\
\text { Falta de apoio dos pais; desestrutura familiar; falta de acompanhamento dos } \\
\text { pais; fatores sociais e emocionais. }\end{array}$ & 3 \\
\hline $\begin{array}{l}\text { Falta de espaço na sala de aula; falta de infraestrutura da escola. } \\
\begin{array}{l}\text { Desinteresse dos alunos; falta de envolvimento dos alunos; falta de } \\
\text { compromisso dos alunos; desmotivação dos alunos em aprender; falta de } \\
\text { curiosidade pelos assuntos acadêmicos. }\end{array}\end{array}$ \\
$\begin{array}{l}\text { Dificuldade de aprendizagem; desempenho ruim dos alunos nas atividades e } \\
\text { avaliações. }\end{array}$ & 12 \\
\hline \begin{tabular}{l} 
Falta de apoio pedagógico na escola. \\
\hline
\end{tabular}
\end{tabular}

Fonte: Elaborado pelos autores. 
A percepção predominante de que os maiores problemas situam-se na falta de interesse dos estudantes, falta de apoio dos pais e na heterogeneidade de níveis de aprendizagem dos/as educandos/as, ao ser problematizada a partir de conceitos como violência simbólica, currículos padronizados, invasão cultural, educação bancária, domesticação, terceirização da culpa, papel da escola na reprodução da desigualdade e do professor como agente da reprodução etc. abriu grandes possibilidades para o diálogo e o conflito de ideias que é próprio da dialogicidade.

O conceito de politicidade ganhou grande destaque quando entramos no terceiro submomento da desconstrução (3. Educação Libertadora no contexto escolar). Ficou evidente que só é possível adjetivar a educação como libertadora porque existe outra que possui uma intencionalidade distinta, não-libertadora. Ao contrário do que se acredita, a educação não é uma prática inocente e desprovida de pressupostos e implicações políticas. Professor/a é agente político. Pode ele/a, por meio de sua prática curricular, reforçar desigualdades, hierarquias, competitividade, preconceitos, compreensão utilitária do conhecimento, indiferença pela vida coletiva, apatia pelo aprendizado, seleções e exclusões etc. Em contrapartida, pela sua prática, pode reforçar o anseio por justiça, igualdade e equidade, solidariedade, tolerância e respeito, compreensão crítica do conhecimento, empatia pela alteridade, desejo de aprender, inclusão, companheirismo, camaradagem etc.

A formação permanente precisa considerar, em sua tarefa, as opções político-pedagógicas dos sujeitos, mesmo que essas sejam para eles não conscientes, pois tanto para o formador, quanto para as/os educadoras/es participantes é necessária a clareza de que não é possível uma formação docente como se fosse uma prática neutra. Freire (2018) afirma que "[...] é preciso saber a favor de que e de quem, portanto contra quêe contra quem pesquisa, ensina ou em nome de quem se envolve em atividades" [...].

O conceito de conscientização ganhou contornos mais claros quando chegamos ao quarto submomento de desconstrução (4. Análise das práticas e concepções vigentes na educação do campo: educação rural, educação do campo e educação do campo na perspectiva freireana). Neste momento, deparamo-nos com a percepção predominante de que educação do campo seria uma visão pedagógica inferior que obstacularizaria o acesso dos/as estudantes aos conteúdos padronizados das escolas urbanas. Essa percepção nos levou à discussão de conceitos como educação rural, educação no campo e educação do campo. Daí houve a tomada de consciência de que a nossa visão de inferioridade da educação do campo tem a ver com a nossa visão de inferioridade do/a camponês/a e da vida no campo, de tal modo que acreditamos que uma educação que parta das necessidades da vida dos/as camponeses, necessariamente leva a um patamar cultural inferior. De acordo com Freire (2016), a tomada de consciência não é ainda conscientização. Para que o processo se complete, é necessário que ocorra a decisão e a adesão a novas ações, novas práticas, novas formas de organização do trabalho pedagógico e, obviamente, a materialização desses novos anseios a partir de novos modos de planejar e concretizar o currículo escolar. 
Nesse momento do trabalho de formação, percebemos que havia um caldo crítico suficiente para iniciar o trabalho coletivo de construção das novas práticas.

O momento de construção e os seus submomentos

O momento da construção consiste no esforço coletivo de elaborar um novo currículo e de planejar novas práticas pedagógicas que superem os limites e contradições do currículo e das práticas pedagógicas desconstruídas no momento anterior. Trata-se agora da fase propositiva da criação de novas perspectivas de trabalho fundamentadas na concepção freireana de temas geradores no contexto da educação do campo.

Neste momento, três conceitos se evidenciaram de modo mais claro: o de participação, o de currículo e o de práxis transformadora.

No primeiro e segundo submomentos da construção, que no quadro-síntese identificamos como submomento 5 (Planejamento, organização e elaboração da estratégia da investigação das situações-problemas, falas significativas e limites explicativos) e 6 (Execução da investigação temática e organização e sistematização de informações coletadas), incentivamos as/os educadoras/es a elaborarem instrumentos para realizar o levantamento dos temas geradores das comunidades em que lecionam e aplicar as questões do instrumento junto aos sujeitos. Destacamos aí o conceito de participação.

Em Freire, a participação, no âmbito da ação pedagógica, é a expressão concreta do sujeito educador/a, que se assume como protagonista dos fazeres curriculares e pedagógicos em que está envolvida/o. Se antes as/os educadoras/es colocavam-se na posição de quem esperava um modelo pronto a ser seguido e aplicado na sala de aula, agora vislumbram a possibilidade de participar efetivamente do processo criativo e inovador de produzir currículo significativo. Para tanto, o ponto de partida foi o levantamento dos problemas comunitários (situações-limites) mais significativos do ponto de vista dos estudantes e/ou dos moradores da comunidade atendida pela escola e, junto com este levantamento, buscar identificar as explicações que os estudantes ou as pessoas da comunidade dão para esses problemas (limites explicativos).

A culminância desses submomentos ocorreu quando as/os educadoras/es selecionaram falas significativas, escolheram uma fala para ocupar o lugar de Tema Gerador do currículo e sistematizaram os dados. Esta sistematização pode ser observada abaixo:

Tema gerador: "falta transporte, as estradas estão muito ruins, são consertadas uma vez por ano pela prefeitura, mas é uma 'daneira', porque é estrada de terra, chove, esburaca e dá lama. Fica difícil levar as crianças no médico e fazer compras na cidade em São Domingos".

- Fala 1: "Falta cuidado com a natureza e o lixo incomoda". 
- Fala 2: "Não identifiquei nenhum dos problemas citados na minha comunidade, contudo percebo que os jovens, crianças, e adultos têm perdido o interesse em viver com a sociedade, preferindo ficar sozinhos, digo acompanhados de seus amigos virtuais, vivendo uma vida virtual".

- Fala 3: "Mais saneamento básico e coleta de lixo, as estradas quando chovem em péssimas condições, o atendimento médico poderia ser mais de uma vez por semana e falta de transporte".

- Fala 4: “Grande problema é o transporte para filho ir à escola, ao médico, fazer compras, porque depende de carona, se for o caso de emergência tem que andar uns $3 \mathrm{~km}$ e depender do horário de ônibus e nem sabe ao certo o horário".

- Fala 5: “O maior problema que a comunidade enfrenta é a falta de colaboração das famílias, tipo criar uma associação onde as pessoas plantassem, colhessem e vendessem no mercado".

- Fala 6: "Falta de oportunidades de emprego e estradas asfaltadas".

- Fala 7: "Sinal de telefone, internet e local para lazer".

- Fala 8: "Mais trabalho e oportunidade de emprego, o valor da diária é de $\mathrm{R} \$ 50,00$ para sustentar a família, internet e carro para andar nas estradas, só os fazendeiros, os ricos têm".

- Fala 9: “O que me incomoda é o sol quente, que me queima quando volto da escola."

- Fala 10: “O preconceito entre nós mesmos... em julgar as pessoas o modo em que vivem".

- Fala 11: "Penso que falta de lazer e cultura; considero o uso de drogas entre os jovens, um grande problema".

O conceito de currículo na perspectiva de Freire ganha materialidade quando, coletivamente, a equipe de educadoras/es passa a identificar conhecimentos demandados pela comunidade a partir da problematização das falas significativas citadas na Tabela 3. Aí temos a razão de ser dos submomentos 7 (Construção da base da rede temática: tema gerador, falas significativas e contratema) e 8 (Construção das dimensões local, microssocial e macrossocial da rede temática) do quadro-síntese.

O currículo contextualizado à realidade local passa a ser palpável no momento em que as/os educadoras/es incidem a reflexão sobre as falas significativas a partir de um olhar curioso e crítico. Para realizar este movimento de problematização, sugerimos às/ aos docentes algumas questões orientadoras da reflexão coletiva: 
- Quais os fatores geográficos locais (relevo, clima, vegetação, hidrografia etc.), físicos e ambientais que devem ser considerados na compreensão do tema e das falas significativas?

- Quais são as atividades econômicas realizadas na comunidade? Quais são as classes sociais existentes na comunidade?

- Quais são os segmentos sociais locais que estão implicados nos conflitos explicitados no tema gerador e nas falas significativas? Ou seja, quais são os segmentos sociais locais que compõem a comunidade?

- Quais os fatores históricos relacionados ao tema gerador e às falas significativas?

- Quais são as características predominantes na mentalidade da comunidade que explicam ou nos ajudam a compreender o tema gerador e as falas significativas?

- Quais são os aspectos da realidade local que explicam e ajudam na compreensão dos problemas evidenciados pelas falas significativas e pelo tema gerador?

Ao realizar o esforço reflexivo e dialógico no sentido de responder a essas questões, as/os educadoras/es passaram a visualizar o momento em que o currículo significativo, comprometido com o desvelamento da realidade local, aparece. Abaixo, podemos observar alguns temas que emergiram a partir da reflexão que realizamos sobre as visões/ falas da comunidade: 
- nascentes

- solo argiloso/barrento

- erosão

- clima tropical

- desmatamento

- individualismo

- rio Pancas

- represas/barragens

- alagamento/enchentes

- medo de falar

- desigualdade social

- café/cafeicultura

- trabalho braçal

- córregos

- produção de leite/queijo/pimenta

- comércio/venda
- gado/pecuária

- eucalipto

- internet no campo

- agrotóxicos

- meeiros

- diaristas

- agricultor familiar

- mov. dos pequenos agricultores

- associação de mulheres

- fazendeiros

- agricultores sindicalizados

- assentamento pomeranos

- associação de agricultores

- linhas de ônibus

- mudança do modo de vida do campo

- autossuficiência no campo

Por fim, o conceito de práxis transformadora se materializa de modo mais específico no submomento 9 (Construção de programações e de atividades pedagógicas contextualizadas). Este submomento consiste na elaboração de sequências de atividades articuladas que tenham como ponto de partida a problematização da fala significativa. Baseamo-nos aqui na perspectiva metodológica dos "três momentos pedagógicos", que, de acordo com Silva (2007), são:

Estudo da Realidade ou Problematização Inicial (PI) - em que se analisa uma situação significativa da realidade local, problematizando-a e questionando os modelos explicativos propostos pela comunidade e alunos (codificação/ descodificação de contradições);

Organização do Conhecimento (OC) ou Aprofundamento Teórico (AT) - em que os conhecimentos sistematizados selecionados são confrontados com a problematização inicial, buscando uma nova concepção das situações analisadas;

Aplicação do conhecimento (AC) ou Plano de Ação (PA) - em que o conhecimento anteriormente construído e apreendido é utilizado para "reler" e reinterpretar a própria realidade, bem como para ser extrapolado para novas situações que apontarão novas problematizações, retroalimentando o processo (SILVA, 2007 p. 15-16). 
A problematização da fala significativa ocorre no primeiro momento pedagógico; a confrontação das percepções das/os estudantes com conceitos, procedimentos, teorias e explicações provenientes do conhecimento sistematizado ocorre no segundo momento pedagógico; a ação transformadora da realidade ou sua ressignificação em uma perspectiva crítica ocorre no terceiro momento.

Infelizmente, não houve tempo suficiente no desenvolvimento do projeto de formação para que as/os educadoras/es pudessem elaborar os seus planos de ação pedagógica a partir dos três momentos citados acima. Para tanto, precisaríamos de mais uns três ou quatro encontros, o que não foi possível de ser realizado por dificuldades de agenda nossa e também da secretaria de educação com a qual a parceria foi firmada. No entanto, esse fato não nos impediu de identificar que o submomento 9 é parte constituinte fundamental da concepção de formação permanente freireana, tal como a reinventamos.

\section{Considerações finais}

O desafio apresentado pelo texto é o de tornar-se um convite para ousar diante do processo formativo a partir da perspectiva do paradigma freireano.

Dentre os desafios que podemos destacar com as experiências vivenciadas está a presença da universidade onde ela ainda não havia chegado, o processo de desalienação docente que se instala, a possibilidade de reencantamento, de descoberta e de assunção da autonomia docente, a ruptura com o silenciamento e o favorecimento de uma postura crítica diante da formação precária, do desconhecimento da base dos princípios freireanos na prática e das dificuldades de leitura de textos científicos no contexto da educação básica.

Torna-se nitidamente perceptível que o trabalho formativo realizado manifesta-se como uma experiência incomum para as/os docentes participantes, principalmente, no que se refere à relação entre a universidade e regiões mais distantes dos campi universitários, experiências que surgem como abertura para romper mitos e muros simbólicos existentes entre o universo acadêmico e o cotidiano das/os professoras/es da educação básica.

No decorrer do trabalho formativo nota-se, após poucos encontros, um certo processo de desalienação, à medida em que aspectos não percebidos da realidade e da educação passam a ser considerados e problematizados. É muito interessante ver professores e professoras se dando conta de aspectos da prática educativa sobre os quais nunca tinham refletido sistematicamente. Em especial, acreditamos que as reflexões sobre a natureza política da ação pedagógica e do trabalho da escola, bem como da tendência reprodutora do fazer pedagógico são muito impactantes, pois possibilitam a superação da visão ingênua em relação ao ofício de professor. 
Quando as/os professoras/es se descobrem como aquelas/es que melhor podem identificar o que as/os educandas/os precisam e que, portanto, podem e devem se tornar protagonistas do planejamento e do fazer pedagógicos, entendemos que um passo fundamental está sendo dado para a transformação. É o momento que surge uma certa rebeldia de quem percebe que as autoridades da educação não deveriam se colocar como donas da verdade e como repassadoras de fórmulas prontas que as/os educadoras/es deverão aplicar. Nesses momentos, veem-se mitos caírem e as/os educadoras/es passam a ver que a falta de autonomia não é uma característica inerente à profissão e sim uma construção histórica a que foram submetidas/os e, consequentemente, percebem que ela deve ser assumida como condição para que o trabalho pedagógico seja de superação e transformação das práticas dominantes, que se distanciam da autêntica realidade formativa, sobre a qual devemos radicalmente repensar.

Recebido em 25/06/2020. Aprovado em 04/07/2020.

\section{Referências}

BRANDÃO, Carlos Rodrigues (org.). Repensando a pesquisa participante. 2. ed. São Paulo: Brasiliense, 1985.

CHIZZOTTI, Antônio. Pesquisa em Ciências Humanas e Sociais. Petrópolis: Vozes, 2006.

FREIRE, Paulo. A educação na cidade. 4. ed. São Paulo: Cortez, 1991.

FREIRE, Paulo. Professora, sim; tia, não: cartas a quem ousa ensinar. 26. ed. São Paulo: Paz e Terra, 2016.

FREIRE, Paulo. Educação como prática da liberdade. 40. ed. Rio de Janeiro/São Paulo: Paz e Terra, 2017.

FREIRE, Paulo. Pedagogia do oprimido. 65. ed. Rio de Janeiro: Paz e Terra, 2018.

MINAYO. Maria Cecília de Souza et al. (Org.) Pesquisa Social: teoria, método e criatividade. 29 ed. Petrópolis, Vozes, 2010.

SAUL, Alexandre. Para mudar a prática da formação continuada de educadores: uma pesquisa inspirada no referencial teórico-metodológico de Paulo Freire. Tese (Doutorado em Educação) Pontifícia Universidade Católica de São Paulo, São Paulo, 2015.

SILVA, Antonio Fernando Gouvêa da. A construção do currículo na perspectiva popular crítica: das falas significativas às práticas contextualizadas. Tese (Doutorado em Educação) - Programa de PósGraduação em Educação: Currículo, Pontifícia Universidade Católica de São Paulo, São Paulo, 2004.

SILVA, Antonio Fernando Gouvêa da. A busca do tema gerador na práxis da Educação Popular. In: SOUXA, Ana Inês (Org.). Metodologia e Sistematização de experiências coletivas populares. Livro 1. $2^{\mathrm{a}}$ ed. rev. e compl. Curitiba: Editora Gráfica Popular, 2007. 